\title{
Ação da uleína sobre a produção de óxido nítrico em células RAEC e B16F10
}

\author{
Wesley M. Souza', Fabrício Brehmer', Lia S. Nakao², Andréa E. M. Stinghen², \\ Cid A. M. Santos ${ }^{1 *}$ \\ ${ }^{1}$ Programa de Pós-Graduação em Ciências Farmacêuticas, Laboratório de Farmacognosia, Universidade Federal \\ do Paraná, 80210-170, Curitiba, PR, Brasil, \\ ${ }^{2}$ Pós-Graduação em Ciências da Saúde, Pontifícia Universidade Católica do Paraná, \\ 80215-901, Curitiba, PR, Brasil
}

\begin{abstract}
RESUMO: Foi investigada a influência da fração rica em alcalóides e da substância majoritária desta fração, uleína, isolada das cascas de Himatanthus lancifolius (Muell. Arg.) Woodson, Apocynaceae, popularmente conhecida como agoniada, sobre a produção de óxido nítrico em células RAEC e B16F10 e a correlação com a atividade antioxidante. Os ensaios de atividade antioxidante foram realizados utilizando os métodos de redução do complexo fosfomolibdênico e o da redução do radical livre DPPH. Os resultados demonstraram uma atividade antioxidante de $59,3 \pm 0,8 \%$ para a fração alcaloídica, enquanto que, para a uleína, esse efeito foi de $0,5 \pm 0,1 \%$ no ensaio de redução do complexo fosfomolibdênico. No ensaio do DPPH, a fração alcaloídica apresentou $\mathrm{IC}_{50}=196,3 \pm 8,9 \mu \mathrm{g} / \mathrm{mL}$ e para a uleína $6475,0 \pm 25,0 \mu \mathrm{g} / \mathrm{mL}$. A uleína, principal alcalóide da fração, estimulou uma produção máxima de óxido nítrico nas concentrações de $0,1 \mu \mathrm{g} /$ $\mathrm{ml}(20,9 \pm 1,4 \mu \mathrm{M})$ e $1 \mu \mathrm{g} / \mathrm{ml}(41,1 \pm 0,2 \mu \mathrm{M})$ utilizando células RAEC e B16F10, respectivamente, demonstrando que o efeito da uleína nas células ocorre através de estímulos nas vias de produção de óxido nítrico e não por um efeito sequestrante de radical livre.
\end{abstract}

Unitermos: Himatanthus lancifolius, Apocynaceae, agoniada, antioxidante, óxido nítrico, uleína.

\begin{abstract}
Uleine effect on the production of nitric oxide in RAEC and B16F10 cells". The influence of the rich alkaloidal fraction and of the major substance in this fraction, uleine, isolated from the barks of Himatanthus lancifolius (Muell. Arg.) Woodson, Apocynaceae, popularly known as agoniada, on the nitric oxide production in RAEC and B16F10 cells and its correlation with the antioxidant activity, were investigated. For the antioxidant activity the methods of formation of a phosphomolybdenum complex and the reduction of the free radical DPPH were used. The results demonstrated an antioxidant activity of $59.3 \pm 0.8 \%$ for the alkaloidal fraction, while for uleine the effect was of $0.5 \pm 0.1 \%$ in the reduction of the phosphomolibdenium method. In the assay of $\mathrm{DPPH}$, the alkaloidal fraction presented $\mathrm{IC}_{50}=196.3 \pm 8.9 \mu \mathrm{g} / \mathrm{mL}$ and for uleine, $6475.0 \pm 25.0$ $\mu \mathrm{g} / \mathrm{mL}$. Uleine also stimulated a maximum nitric oxide production in the concentrations of 0.1 $\mu \mathrm{g} / \mathrm{mL}(20.9 \pm 1.4 \mu \mathrm{M})$ and $1 \mu \mathrm{g} / \mathrm{mL}(41.1 \pm 0.2 \mu \mathrm{M})$ using RAEC and B16F10 cells, respectively, demonstrating that the effect of uleine in the cells occurs by promoting the nitric oxide production pathway, but not through a free radical scavenger effect.
\end{abstract}

Keywords: Himatanthus lancifolius, Apocynaceae, agoniada, antioxidant, uleine.

\section{INTRODUÇÃO}

A família Apocynaceae possui cerca de 200 gêneros e 2000 espécies, de distribuição tropical e subtropical, podendo chegar até regiões temperadas. O gênero Himatanthus foi descrito por Willdenow (Woodson, 1951) e consiste de árvores, arbustos ou subarbustos. Himatanthus lancifolius (Muell. Arg.) Woodson, Apocynaceae, previamente denominada Plumeria lancifolia Muell. Arg., popularmente conhecida como agoniada, é uma planta nativa que cresce em diferente áreas do Brasil, particularmente nos estados de Minas Gerais, Espírito Santo, Rio Grande do Sul, Goiás e Amazônia, sendo descrita oficialmente na Farmacopéia Brasileira I (Brandão et al., 2006). São indicadas na medicina tradicional para o tratamento de várias doenças de pele, febrífuga, emenagoga, purgativa, antiúlcera, asma, sífilis e principalmente como estimulante das contrações uterinas, auxiliando na concepção e regularizando a menstruação (Corrêa et al., 1998).

Estudos com os extratos das cascas dessa planta demonstraram preliminarmente a presença de uleína (1) e (+)-demetoxiaspidospermina (França et al., 2000). A fração de alcalóides, rica em uleína, também apresentou atividade gastroprotetora (Baggio et al., 2005) e efeitos sobre a resposta em musculatura lisa vascular e não- 
vascular (Rattmann et al., 2005). Em outro trabalho Machado Júnior et al. (2006) utilizaram a citometria de fluxo para avaliar a atividade imunomoduladora do extrato etanólico de $H$. lancifolius sobre células mononucleares humanas.

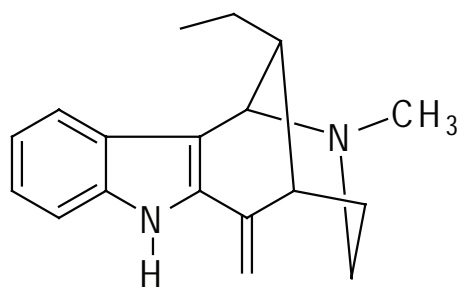

1

O óxido nítrico (NO) tem despontado nos últimos anos como sendo uma molécula biossintetizada envolvida na regulação de diversas funções fisiológicas, tais como homeostase dos vasos sanguíneos, transmissão neuronal e resposta do hospedeiro à infecção. Ele é sintetizado pelas enzimas óxido nítrico sintases (NOS), que convertem a L-arginina em L-citrulina e NO, com o auxílio de oxigênio molecular e NADPH (Moncada et al., 1991). É um gás lipossolúvel que possui elétron não pareado que o faz altamente reativo (Cerqueira; Yoshida, 2002) e está envolvido em vários outros processos celulares importantes, além da sua ação em células musculares lisas vasculares. Em altas concentrações é citotóxico, facilmente inativado pelo oxigênio (Archer, 1993) ou superóxido dismutase (Gryglewski et al., 1986), tendo uma meia vida curta e especificidade mínima de reações (Nathan, 1992). Difunde-se livremente entre as membranas celulares e interage com um grande número de alvos ativando vias de sinalização produzidas pelas células endoteliais e musculares lisas. Assim, dependendo do fluxo e da quantidade produzida, o NO nos sistemas biológicos tem dois efeitos primordiais. $\mathrm{O}$ primeiro é sua atuação como mensageiro, pelas quais as células se comunicam umas com as outras. $\mathrm{O}$ segundo se refere às suas propriedades tóxicas usadas pelo sistema imunológico para diminuir a proliferação de organismos invasores (Marletta, 1994).

Neste trabalho foram avaliadas as capacidades antioxidantes da fração alcaloídica e da uleína separadamente e comparadas com um padrão clássico de ácido ascórbico utilizando dois métodos: redução do complexo fosfomolibdênico e seqüestro do radical DPPH. A ação da uleína sobre a produção de óxido nítrico (NO) também foi avaliada utilizando células endoteliais de aorta de coelho (RAEC) e células melanoma de camundongos (B16F10).

\section{MATERIAL E MÉTODOS}

\section{Material botânico}

\section{Cascas de Himatanthus lancifolius}

kg) foram adquiridas no mercado formal de plantas medicinais na região metropolitana de São Paulo, Brasil, e a identificação da espécie foi feita pelos próprios autores através de análise farmacognóstica, segundo a Farmacopéia Brasileira I e por comparação macroscópica e microscópica com amostra autêntica. Uma amostra do material botânico utilizado encontra-se depositada no Laboratório de Farmacognosia da UFPR, onde permanece como material de referência e estudo. As cascas da planta foram moídas, desengorduradas em Soxhlet com éter de petróleo e em seguida submetida à maceração com solução aquosa de ácido clorídrico $1 \%$ (v/v) e extraída até reação negativa frente ao reagente de Dragendorff. $\mathrm{O}$ extrato obtido foi filtrado e concentrado em rotavapor $\left(40{ }^{\circ} \mathrm{C}\right)$ até aproximadamente $1 / 5$ do volume inicial e posteriormente alcalinizado com carbonato de sódio $(\mathrm{pH}$ 10) e submetido à partição com clorofórmio. $\mathrm{O}$ extrato orgânico foi evaporado sob pressão reduzida, obtendo-se 17,29 g da fração rica em alcalóides (FA). Essa fração foi suspensa em solução aquosa de ácido clorídrico $1 \%$, filtrada e concentrada em rotavapor até secura e os ensaios foram realizados com os alcalóides na forma de cloridrato.

\section{Fracionamento e isolamento da uleína}

Uma porção da fração de alcalóides (3 g) foi submetida à cromatografia em coluna de sílica gel 70230 mesh (60 g) e eluída com um gradiente de $n$-hexano, $n$-hexano:tolueno, tolueno, tolueno:diclorometano, diclorometano, diclorometano:clorofórmio, clorofórmio, clorofórmio:acetato de etila, acetato de etila, acetato de etila:etanol e etanol. Desse fracionamento foram obtidas 475 frações, que foram submetidas à cromatografia de camada delgada (fase móvel: $n$-hexano:acetato de etila: metanol:dietilamina - 5:4:0,8:0,2.), revelada com reagente de Dragendorff ou sulfato cérico amoniacal seguida por aquecimento. Após verificação das cromatografias de camada delgada (CCD), frações com mesmo perfil cromatográfico foram combinadas rendendo 33 frações denominadas U1 até U33. As frações U12-U20 foram novamente reunidas e submetidas à cromatografia preparativa em sílica gel $(20 \times 20 \mathrm{~cm})$ rendendo quatro manchas bem definidas, denominadas R1D1, R1D2, R1D3 e R1D4. A fração R1D1 $\left(R_{f}=0,37\right)$ foi resubmetida a cromatografia em sílica gel (10 g) usando como solvente clorofórmio:metanol (99,5:0,5), onde foi obtido $0,2051 \mathrm{~g}$ $(0,0041 \%)$ de um composto puro o qual foi submetido a várias recristalizações em clorofórmio:metanol e seco em Abderhauden na presença de pentóxido de fósforo. Investigação química do composto isolado por métodos espectrométricos (UV, IV, EM e RNM) e por comparação com amostra padrão e dados da literatura, indicou tratarse do composto uleína (1) (Joule; Djerassi, 1964; Ohashi et al., 1964; França et al., 2000).

\section{Testes de atividade antioxidante}




\section{Avaliação da atividade pela formação do complexo fosfomolibdênico}

Uma alíquota $(0,3 \mathrm{~mL})$ da solução estoque da fração de alcalóides (FA) e do composto isolado 1 (200 $\mu \mathrm{g} / \mathrm{mL}$ ), foram adicionadas em tubos de ensaios com a solução reagente ( $3 \mathrm{~mL}, 0,6 \mathrm{M}$ de ácido sulfúrico, $28 \mathrm{mM}$ de fosfato de sódio e $4 \mathrm{mM}$ de molibdato de amônio). Os tubos foram incubados em banho-maria a $95{ }^{\circ} \mathrm{C}$ por 90 minutos. Após resfriamento, a absorvância foi mensurada em aparelho UV a $695 \mathrm{~nm}$ contra o branco. A absorvância do padrão de ácido ascórbico nas mesmas concentrações e condições de análise foi determinada. Os resultados foram expressos na forma de atividade antioxidante relativa $\left(\mathrm{AAR}_{\%}\right)$ em relação ao ácido ascórbico, conforme indicado por Prieto et al. (1999).

\section{Ensaio fotométrico com DPPH}

A fração de alcalóides (FA) e o composto isolado foram diluídos em etanol de forma a serem obtidas soluções nas concentrações de $10,25,50,125$, $250 \mu \mathrm{g} / \mathrm{mL}$ e $75,250,500,750 \mu \mathrm{g} / \mathrm{mL}$, respectivamente. Na seqüência, as soluções obtidas $(2,5 \mathrm{~mL})$ foram incorporadas à solução etanólica de DPPH (1,1-difenil2-picrilhidrazil - $1 \mathrm{~mL}, 0,3 \mathrm{mM}$ ). A solução controle foi formada apenas pela mistura de etanol $(1 \mathrm{~mL})$ com as soluções obtidas $(2,5 \mathrm{~mL})$, de modo que para cada concentração exista um branco correspondente. Todas as reações foram feitas em triplicata e nas mesmas condições de análises ( 30 minutos, $25^{\circ} \mathrm{C}$ ). Após o tempo de reação, as absorvâncias das amostras foram determinadas a $518 \mathrm{~nm}$ em espectrofotômetro UV 1601 Shimadzu e convertidos em porcentagem de atividade antioxidante $\left(\mathrm{IC}_{\%}\right)$. Os resultados obtidos foram comparados com o padrão de ácido ascórbico. A expressão dos resultados foi dada pela $\mathrm{IC}_{50}(\mathrm{em} \mu \mathrm{g} / \mathrm{mL})$, calculada com auxílio da equação da reta interpolada com os dados de concentração (eixo das abcissas) e $\mathrm{IC}_{\%}$ (eixo das ordenadas). Etanol e a solução estoque foram usados como branco. Solução de DPPH e etanol foram usados como controle negativo (Mensor et al., 2001).

\section{Dosagem do óxido nítrico}

Células endoteliais de aorta de coelho (RAEC) gentilmente doadas pela Dra. Helena Nader (UNIFESP) e células B16F10 (células melanoma de camundongos - ATCC CRL-6475) foram cultivadas em meio apropriado até confluência e mantidas em Banco de Células do NIMA (Núcleo de Investigações Moleculares Avançadas), Centro de Ciências Biológicas e da Saúde da Pontifícia Universidade Católica do Paraná. As células foram mantidas em meio de cultura DMEM/F12 (RAEC) e RPMI 1640 (B16F10), suplementado com $10 \%$ de soro fetal bovino, $100 \mathrm{U} / \mathrm{mL}$ de penicilina e 10 $\mu \mathrm{g} / \mathrm{mL}$ de gentamicina. As células foram plaqueadas em

placas de 96 poços na densidade de $1 \times 10^{5}$ células $/ \mathrm{mL}$, volume final de $400 \mu \mathrm{L}$ e incubadas a $37{ }^{\circ} \mathrm{C}$ com $5 \%$ de $\mathrm{CO}_{2}$ e atmosfera umidificada, sendo o meio trocado a cada 48 horas até confluência das células. Para o teste de viabilidade celular e citotoxicidade foi usado o teste com azul de Trypan (Merchant; Kahn, 1964). A partir do composto isolado 1 (uleína), foram feitas soluções estoques, a $2 \mathrm{mg} / \mathrm{mL}$ em meio DMEM/F12 (Dulbecco’s Modified Eagle’s Medium) e RPMI (RPMI 1640 Medium) em condições estéreis e armazenadas à $-8{ }^{\circ} \mathrm{C}$ até o momento do uso. Após os cultivos celulares atingirem confluência desejada, a uleína foi adicionada nas concentrações de $0,01,0,1,1,10$ e $100 \mu \mathrm{g} / \mathrm{mL}$, isoladamente ou em associação com nitro-L-arginina metil éster (L-NAME - $1 \mu \mathrm{g} / \mathrm{mL}$ ), um inibidor da NOS. Um estimulador da iNOS também foi utilizado (LPS - 100 $\mathrm{ng} / \mathrm{mL}$ ). Vinte e quatro horas após a ativação, um volume de $100 \mu \mathrm{L}$ do sobrenadante foi retirado e a ele adicionado igual volume do reagente de Griess (sulfanilamida 1\% (p/v) em $\mathrm{H}_{3} \mathrm{PO}_{4} 5 \%$ + alfa-naftil-etilenodiamina 0,1\% (v/ v) em água) (Green et al., 1982). A produção de NO foi estimada pela quantificação do metabólito estável de NO, o nitrito. A absorvância a $540 \mathrm{~nm}$ foi medida em leitor de Elisa Spectra Softmax após 10 minutos. A concentração de nitrito no sobrenadante foi quantificada a partir de uma curva padrão com concentrações conhecidas de nitrito de sódio em $\mu \mathrm{M}$.

\section{Análise estatística}

Os resultados foram apresentados como média \pm e.p.m, analisados usando pacote estatístico Sigmastat ${ }^{\circledR}$ para Windows (Versão 3.5, USA) e, para a comparação entre os grupos, foi utilizado ANOVA seguido de teste de Tukey ou Kruskal-Wallis, com valores de $P \leq 0,001$ considerados estatisticamente significativos.

\section{RESULTADOS E DISCUSSÃO}

Os resultados obtidos no sistema de redução do complexo fosfomolibdênico indicam que nem a fração alcaloídica (FA) nem a uleína apresentaram atividade antioxidante relativa $\left(\mathrm{AAR}_{\circ}\right)$ considerável e ambas inferiores ao padrão de ácido ascórbico. Para a FA a média da $\mathrm{AAR}_{0}$ (ácido ascórbico) foi igual a 59,3 $\pm 0,8 \%$, enquanto que para a uleína, foi de $0,5 \pm 0,1 \%$ em relação a $100 \%$ do total de atividade antioxidante atribuida ao ácido ascórbico. A FA apresentou uma maior $\mathrm{AAR}_{\%}$ em relação a uleína, significando possuir uma maior disponibilidade eletrônica capaz de reduzir o complexo fosfomolibdênico. Análise dessa fração (FA) evidenciou, além dos alcalóides, a presença de compostos fenólicos (taninos) o que sugere serem os principais responsáveis pela atividade antioxidante (França et al., 2000).

De maneira similar, os resultados obtidos no teste do sequestro de radical utilizando-se DPPH não demonstraram atividade da fração alcaloídica $\left(\mathrm{IC}_{50}=\right.$ 
$196,3 \pm 8,9 \mu \mathrm{g} / \mathrm{mL}$ ) e da uleína $\left(\mathrm{IC}_{50}=6475,0 \pm 25,0 \mu \mathrm{g} /\right.$ $\mathrm{mL}$ ), sendo inferior ao apresentado pelo padrão de ácido ascórbico ( $\mathrm{IC}_{50}=32,0 \pm 0,3 \mu \mathrm{g} / \mathrm{mL}$ ), corroborando com os resultados obtidos no ensaio da redução do complexo fosfomolibdênico. Conforme demonstrado para o ácido ascórbico, um conhecido composto com disponibilidade eletrônica capaz de reduzir o DPPH, quanto menor o valor determinado para a $\mathrm{IC}_{50}$, mais antioxidante é o composto ou fração testada.

A presença de doses crescentes de uleína adicionados ao cultivo resultou em um aumento na produção de NO somente em algumas concentrações. Como pode ser observado na figura 1 e 2 , a produção de NO em células endoteliais (RAEC) mostrou uma produção máxima na dose de $0,1 \mu \mathrm{g} / \mathrm{mL}(20,9 \pm 1,4$ $\mu \mathrm{M}$ de nitrito) enquanto para as células B16F10 foi de 41,1 $\pm 0,2 \mu \mathrm{M}$ de nitrito na concentração de $1 \mu \mathrm{g} / \mathrm{mL}$ de uleína. A produção de NO dependente de NOS foi testada pela incubação de células RAEC e B16F10 com lipopolissacarideo bacteriano (LPS, $100 \mathrm{ng} / \mathrm{mL}$ ), o qual estimulou a produção de óxido nítrico em $30,8 \pm 1,8$ e. $47,1 \pm 2,0 . \mu M$ respectivamente, e pela inibição da produção com L-NAME em todas as concentrações de uleína utilizadas. Para se ter certeza de que o aumento na produção de NO não era decorrente de morte celular, teste de viabilidade das células foi realizado após o ensaio e observou-se que em todas as concentrações avaliadas a viabilidade das células sempre foi superior a 94\% (dados não demonstrados). As concentrações de 0,01, 10 e 100 $\mu \mathrm{g} / \mathrm{mL}$ de uleína não favoreceram produção de NO em células RAEC, e em células B16F10 não houve produção significativa nas concentrações de 0,01, 0,1, 10 e 100 $\mu \mathrm{g} / \mathrm{mL}$, quando comparadas ao controle contendo células não estimuladas (3,7 $\pm 0,2 \mu \mathrm{M}$ para RAEC e 2,4 $\pm 0,1 \mu \mathrm{M}$ . para B16F10). Matheus et al. (2003) demonstraram que células RAW 264.7 estimuladas com lipopolissacarídeo bacteriano $(100 \mathrm{ng} / \mathrm{mL})$ e interferon-alfa $(10 \mathrm{U} / \mathrm{mL})$ produziram uma grande quantidade de óxido nítrico (35 $\mu \mathrm{M})$ quando comparadas com células não estimuladas (3 $\mu \mathrm{M})$. Fushiya et al. (1999) demonstraram a inibição da síntese de NO em macrófagos utilizando extrato metanólico obtido das partes aéreas de $C$. droserifolia e com substâncias isoladas de outras plantas tal como Lycium chinese (Kim et al., 1997) e Magnolia sieboldii (Park et al., 1996). Cho et al. (2001) demonstraram que a siringina, um glicosideo fenólico isolado de uma variedade de plantas medicinais tais como Magnolia sieboldii e Tinospora cordifolia, não atenuou a produção de óxido nítrico e viabilidade celular em altas concentrações.

$\mathrm{O}$ NO pode ser um oxidante ou um redutor, dependendo das condições em que encontra-se, da mesma forma em que pode modular reações inflamatórias e antiinflamatórias dependendo do tipo celular e do estimulo o qual é submetido (Adams, 1996) (Cerqueira; Yoshida, 2002). Algumas plantas que apresentam atividade antiinflamatória têm sido reconhecidas pela sua capacidade de inibir produção de NO (Choi; Hwang, 2005) como também pela sua capacidade de estimular a produção de NO (Heo et al., 2004). Estudos recentes mostraram que a fração rica em alcalóides das cascas de Himatanthus lancifolius, dos quais a uleína é o principal constituinte, é capaz de efetuar mudanças na resposta vascular e não vascular da musculatura lisa de aorta de ratos desprovidos de endotélio produzindo relaxamento, e esse evento pode envolver o bloqueio da entrada de cálcio, alterações na mobilização de cálcio intracelular e também distúrbios na habilidade das células de usar o cálcio para eventos contráteis (Rattmann et al., 2005). Mollace et al. (1991) citam que o NO podem ser produzido diretamente pelas células musculares lisas, podendo regular as atividades dessas células por um mecanismo dependente da GMPc. O aumento do NO observado nesse trabalho, pode ser devido a uma ação estimulante direta nas vias de produção de NO nas células RAEC (células endoteliais de aorta de coelho) e B16F10 (células melanoma de camundongos), e não por uma ação sequestrante do radical livre, confirmado pelos resultados dos ensaios de atividade antioxidante, o qual demonstram a baixa atividade da uleína nos dois métodos utilizados (redução do DPPH e redução do ácido fosfomolibdênico), não sendo a produção de NO, nesse caso, necessariamente dependente da presença do endotélio. Palmer et al. (1988) e Wu e Morris (1998) descreveram que várias outras células podem utilizar a L-arginina para sintetizar NO, não somente células endoteliais, comprovadas pelas células tumorais B16F10 aqui estudadas, com produção de óxido nítrico superior ao apresentado pelas células endoteliais na concentração de $1 \mu \mathrm{g} / \mathrm{mL}$. Choi e Hwang (2005) demonstraram que o NO representa uma via principal tal como agente neurotransmissor, vasodilatador e regulador imune em uma variedade de tecidos em concentrações fisiológicas. Segundo Salvemini et al. (1996) o NO é um potente vasodilatador e seu envolvimento na resposta inflamatória pode ter relação com sua habilidade em aumentar a permeabilidade vascular e o edema através de mudanças no fluxo sanguíneo local e do aumento na produção de prostaglandinas proinflamatórias.

O aumento da produção de NO pela uleína pode justificar o uso popular da droga agoniada como emenagoga e em distúrbios pós-menopausa devido a atividade relaxante da musculatura lisa pelos alcalóides de $H$. lancifolius. Diversos alcalóides indólicos são conhecidos pelas suas atividades vasodilatadoras (Ozaki, 1990; Yuzurihara et al., 2002) sugerindo que a uleína possa também estar fazendo parte dos compostos que apresentam essa atividade. Corrêa et al. (1998) citam que o uso contínuo da agoniada podem interferir no processo de coagulação, o que nos leva a sugerir uma provável ação do NO no interior das plaquetas, pois de modo análogo ao discutido para as células musculares lisas endoteliais, o NO promove um aumento de GMPc e consequentemente diminuição de cálcio livre. Como o cálcio livre é essencial para o processo de ativação plaquetária, esse processo 


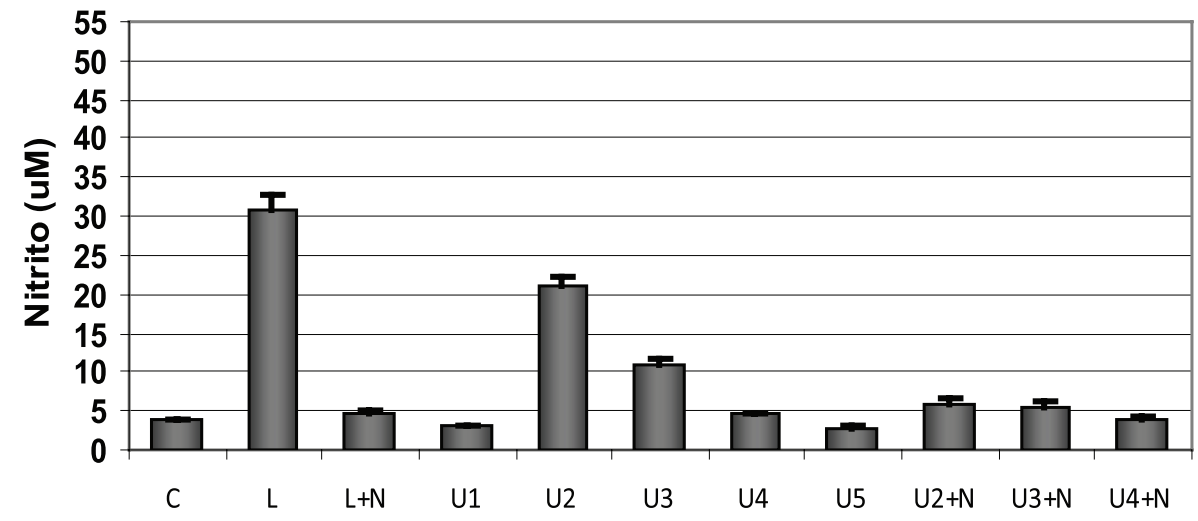

Figura 1. Efeito da uleína (U), lipopolissacarídeo (L) e L-NAME (N) na produção de óxido nítrico em células endoteliais de aorta de coelho (RAEC). Células endoteliais foram tratadas com uleína (U1-0,01; U2-0,1; U3-1; U4-10; U5-100 $\mu$ g/mL), lipopolissacarideo (100 ng/mL) e L-NAME (1 $\mu \mathrm{g} / \mathrm{mL})$, isolados ou em associação. Cada coluna representa à média \pm e.p.m da quantificação do nitrito medida em espectrofotômetro a $540 \mathrm{~nm}(\mathrm{n}=3-4),{ }^{*} P \leq 0,001$ (ANOVA seguido de teste de Kruskal-Wallis).

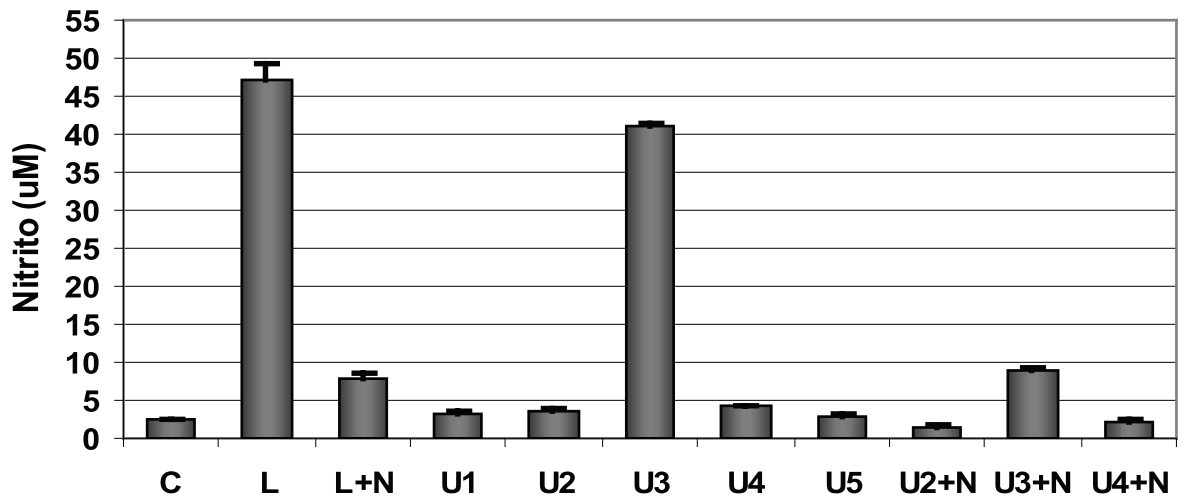

Figura 2. Efeito da uleína (U), lipopolissacarídeo (L) e L-NAME (N) na produção de óxido nítrico em células melanoma de camundongos (B16F10 - ATCC CRL-6475). Células melanoma foram tratadas com uleína (U1-0,01; U2-0,1; U3-1; U4-10; U5$100 \mu \mathrm{g} / \mathrm{mL})$, lipopolissacarideo $(100 \mathrm{ng} / \mathrm{mL})$ e L-NAME $(1 \mu \mathrm{g} / \mathrm{mL})$, isolados ou em associação. Cada coluna representa a média \pm e.p.m da quantificação do nitrito medida em espectrofotômetro a $540 \mathrm{~nm}(\mathrm{n}=3-4),{ }^{*} P \leq 0,001$ (ANOVA seguido de teste de Tukey).

será inibido (Wolin, 2000).

Embora o NO seja objeto de muitas pesquisas e de um grande número de publicações, ainda existem muitas questões controversas e numerosas dúvidas que precisam ser esclarecidas, o que também acontece com esse trabalho, como por exemplo, qual a principal enzima que participa da via de produção de NO que são estimuladas pela uleína.

\section{AGRADECIMENTOS}

Os autores são gratos ao CNPq pelo suporte financeiro (concessão \# 472018/2004-3), Departamento de Bioquímica (UFPR) pela obtenção dos espectros de ${ }^{1} \mathrm{H}-\mathrm{NMR}$ e ${ }^{13} \mathrm{C}$-NMR e a Dra. Helena Nader (UNIFESP) pela doação de células RAEC.

\section{REFERÊNCIAS}

Adams HR 1996. Physiologic, pathophysiologic, and therapeutic implications for endogenous nitric oxide. $J$ Am Vet Med Assoc 209: 1297-1302.

Archer S 1993. Measurement of nitric oxide in biological models. Faseb J 7: 349-360.

Baggio CH, De Martini OG, Souza WM, Santos CAM, Torres LM, Rieck L, Marques MCA, Mesia-Vela S 2005. Gastroprotective mechanisms of indole alkaloids from Himatanthus lancifolius. Planta Med 71: 733-738.

Brandão MGL, Cosenza GP, Moreira RA, Monte-Mor RLM 2006. Medicinal plants and other botanical products from the Brazilian Official Pharmacopoeia. Rev Bras Farmacogn 16: 408-420.

Cerqueira NF, Yoshida WB 2002. Óxido nítrico: Revisão. Acta 
Cirurgica Brasileira 17: 417-423.

Cho JY, Nam KH, Kim AR, Park J, Yoo ES, Baik KU, Yu YH, Park MH2001. In-vitroandin-vivoimmunomodulatory effects of syringin. J Pharm Pharmacol 53: 12871294.

Choi EM, Hwang JK 2005. Effects of Morus alba leaf extract on the production of nitric oxide, prostaglandin E2 and cytokines in RAW264.7 macrophages. Fitoterapia 76: 608-613.

Corrêa AD, Batista RS, Quintas LEM 1998. Do cultivo a terapêutica. Plantas medicinais. Petrópolis, Vozes, 69p.

França OO, Brown RT, Santos CAM 2000. Uleine and demethoxyaspidospermine from the bark of Plumeria lancifolia. Fitoterapia 71: 208-210.

Fushiya S, Kishi Y, Hattori K, Batkhuu J, Takano F, Singab AN, Okuyama T 1999. Flavonoids from Cleome droserifolia suppress NO production in activated macrophages in vitro. Planta Med 65: 404-407.

Green LC, Wagner DA, Glogowsk J, Skipper PL, Wishnok JS, Tannembaum SR 1982. Analysis of nitrate, nitrite, and [15N]nitrate in biological fluids. Anal Biochem 126: 131-138.

Gryglewski RJ, Palmer RM, Moncada S 1986. Superoxide anion is involved in the breakdown of endothelium-derived vascular relaxing factor. Nature 320: 454-456.

Heo KS, Lee SJ, Ko JH, Lim K, Lim KT 2004. Glycoprotein isolated from Solanum nigrum L. inhibits the DNAbinding activities of NF-kappaB and AP-1, and increases the production of nitric oxide in TPAstimulated MCF-7 cells. Toxicol In Vitro 18: 755-763.

Joule JA, Djerassi C 1964. Alkaloids studies XLIV. Mass spectrometry in structural and stereochemical problems. XLII. Some aspects of the chemistry and mass spectrometry of uleine. J Am Chem Soc 15: 2777-2789.

Kim HP, Kim SY, Lee EJ, Kim YC, Kim YC 1997. Zeaxanthin dipalmitate from Lycium chinense has hepatoprotective activity. Res Commun Mol Pathol Pharmacol 97: 301-314.

Machado Junior JC, Florão A, Mattana FVR, Rocha FH, Santos CAM, Weffort-Santos AM 2006. A citometria de fluxo como instrumento de avaliação da atividade imunomodulatória de extratos e substâncias isoladas de plantas medicinais. Rev Bras Farmacogn 16(Supl.): 645-655.

Marletta MA 1994. Nitric oxide synthase: aspects concerning structure and catalysis. Cell 78: 927-930.

Matheus ME, Mantovani ISB, Santos GB, Fernandes SOB, Menezes FS, Fernandes PB 2003. Ação de extratos de Açai (Euterpe oleraceae Maet.) sobre a produção de óxido nítrico em células RAW 264.7. Rev Bras Farmacogn 13(Supl.): 3-5.

Mensor LL, Menezes FS, Leitão GG, Reis AS, Santos TC, Coube CS, Leitão SG 2001. Screening of Brazilian plant extracts for antioxidant activity by the use of DPPH free radical method. Phytother Res 15: 127-
130.

Merchant D, Kahn R 1964. Handbook of Cell and Organ Culture. Broken Arrow, Burgess Publishing, 191p.

Mollace V, Salvemini, D, Anggard E, Vane J 1991. Nitric oxide from vascular smooth muscle cells: regulation of platelet reactivity and smooth muscle cell guanylate cyclase. Brit J Pharmacol 104: 633-638.

Moncada S, Palmer RM, Higgs ES 1991. Nitric oxide: physiology, pathophysiology, and pharmacology. Pharmacol Rev 43: 109-142.

Nathan C 1992. Nitric oxide as a secretory product of mammalian cells. Faseb J 6: 3051-3064.

Ohashi M, Joule JA, Gilbert B, Djerassi C 1964. The structures of five new Aspidosperma alkaloids related to uleine. Experientia 20: 363-364.

Ozaki Y 1990. Vasodilative effects of indole alkaloids obtained from domestic plants, Uncaria rhynchophylla Miq. and Amsonia elliptica Roem. et Schult. Nippon Yakurigaku Zasshi 95: 47-54.

Palmer RM, Ashton DS, Moncada S 1988. Vascular endothelial cells synthesize nitric oxide from L-arginine. Nature 333: 664-666.

Park HJ, Jung WT, Basnet P, Kadota S, Namba T 1996. Syringin 4-O-beta-glucoside, a new phenylpropanoid glycoside, and costunolide, a nitric oxide synthase inhibitor, from the stem bark of Magnolia sieboldii. J Nat Prod 59: 1128-1130.

Prieto P, Pineda M, Aguilar M 1999. Spectrophotometric quantitation of antioxidant capacity through the formation of a phosphomolybdenum complex: specific application to the determination of vitamin E. Anal Biochem 269: 337-341.

Rattmann YD, Terluk MR, Souza WM, Santos CAM, Biavatti MW, Torres LB, Mesia-Vela S, Rieck L, Silva JES 2005. Effects of alkaloids of Himatanthus lancifolius (Muell. Arg.) Woodson, Apocynaceae, on smooth muscle responsiveness. J Ethnopharmacol 100: 268275.

Salvemini D, Wang ZQ, Wyatt PS, Bourdon DM, Marino MH, Manning PT, Currie MG 1996. Nitric oxide: a key mediator in the early and late phase of carrageenaninduced rat paw inflammation. Brit J Pharmacol 118: 829-838.

Wolin MS 2000. Interactions of oxidants with vascular signaling systems. Arterioscler Thromb Vasc Biol 20: 14301442.

Woodson RE 1951. Studies in the Apocynaceae. An interin revision of the genus Aspidosperma Mart. et Zucc. Annals of the Missouri Botanical Garden 25: 200.

Wu G, Morris SM 1998. Arginine metabolism: nitric oxide and beyond. Biochem J 336: 1-17.

Yuzurihara M, Ikarashi Y, Goto K, SakakibaraI, HayakawaT, Sasaki H 2002. Geissoschizine methyl ether, an indole alkaloid extracted from Uncariae ramulus et Uncus, is a potent vasorelaxant of isolated rat aorta. Eur $J$ Pharmacol 444: 183-189. 